\title{
Toxicokinetics/toxicodynamics of arsenic for farmed juvenile milkfish Chanos chanos and human consumption risk in BFD-endemic area of Taiwan
}

\author{
Berry Yun-Hua Chou ${ }^{\text {a }}$, Chung-Min Liao ${ }^{a, *}$, Ming-Chao Lin ${ }^{b}$, Hsu-Hui Cheng ${ }^{b}$ \\ a Ecotoxicological Modeling Center, Department of Bioenvironmental Systems Engineering, National Taiwan University, Taipei, 10617 Taiwan, ROC \\ ${ }^{\mathrm{b}}$ General Education Center/Graduate Institute of Environmental Management, Nanhua University, Chiayi, 622 Taiwan, ROC
}

Received 17 August 2005; accepted 2 January 2006

Available online 2 March 2006

\begin{abstract}
This paper presents a toxicokinetic/toxicodynamic analysis to appraise arsenic (As) bioaccumulation in farmed juvenile milkfish Chanos chanos at blackfoot disease (BFD)-endemic area in Taiwan, whereas probabilistic incremental lifetime cancer risk (ILCR) and hazard quotient (HQ) models are also employed to assess the range of exposures for the fishers and non-fishers who eat the contaminated fish. We conducted a 7-day exposure experiment to obtain toxicokinetic parameters, whereas a simple critical body burden toxicity model was verified with LC50( $t)$ data obtained from a 7-day acute toxicity bioassay. Acute toxicity bioassay indicates that 96-h LC50 for juvenile milkfish exposed to As is 7.29 (95\% CI: 3.10-10.47) $\mathrm{mg} \mathrm{l}^{-1}$. Our risk analysis for milkfish reared in BFD-endemic area indicates a low likelihood that survival is being affected by waterborne As. Human risk analysis demonstrates that $90 \%$-tile probability exposure ILCRs for fishers in BFD-endemic area have orders of magnitude of $10^{-3}$, indicating a high potential carcinogenic risk, whereas there is no significant cancer risk for non-fishers (ILCRs around $10^{-5}$ ). All predicted 90\%-tiles of HQ are less than 1 for non-fishers, yet larger than 10 for fishers which indicate larger contributions from farmed milkfish consumptions. Sensitivity analysis indicates that to increase the accuracy of the results, efforts should focus on a better definition of probability distributions for milkfish daily consumption rate and As level in milkfish. Here we show that theoretical human health risks for consuming As-contaminated milkfish in the BFD-endemic area are alarming under a conservative condition based on a probabilistic risk assessment model.
\end{abstract}

(C) 2006 Elsevier Ltd. All rights reserved.

Keywords: Arsenic; Milkfish; Toxicokinetics; Toxicodynamics; Toxicity; Blackfoot disease; Human health; Probabilistic risk assessment

\section{Introduction}

Systemic and chronic exposure to arsenic (As) is known to lead to serious disorders, such as vascular diseases (Blackfoot disease (BFD) and hypertension) and irritations of the skin and mucous membranes as well as dermatitis, keratosis, and melanosis (ATSDR, 2000; USEPA, 1995). BFD, a unique peripheral vascular disease that ends with dry gangrene and spontaneous amputation of affected extremities in the southwestern coastal area of Taiwan (Chen et al., 2001). Inorganic arsenic is a human carcinogen, and ingestion of inorganic arsenic increases the risk of developing cancer of the bladder, liver, kidney, and skin (Abernathy et al., 2003; Yu et al., 2003). The clinical mani-

\footnotetext{
* Corresponding author. Tel.: +886 22363 4512; fax: +8862 23626433 .
}

E-mail address: cmliao@ntu.edu.tw (C.-M. Liao). festations of chronic arsenic intoxication are referred to as arsenicosis (hyperpigmentation and keratosis). At present, there is no effective therapy for arsenicosis, and consequently, treatment involves reducing arsenic exposure and providing specific drugs for recovery and/or averting disease progression.

Milkfish (Chanos chanos), a traditional food fish for people in Taiwan, is appreciated for their delicacy and is the second most important farmed fish in Taiwan. For decades, the milkfish industry ranked first in the aquaculture industry of Taiwan (Chou et al., 2003). Furthermore, milkfish is the second highest consumed fish in Taiwan (Fisheries Statistical Year Book, 2003). Aquaculture of milkfish is therefore a promising business. Most milkfish ponds are located at the southwest coasts of Taiwan, where the inhabitants used to suffer from BFD due to long-term exposure to inorganic As in groundwater (Chen et al., 2001). Nowadays, most of the people living in these areas do not drink 
water from groundwater because tap water has been made available in this area. However, groundwater is still used for aquaculture (Lin et al., 2001). Han et al. (1998) reported that the As in milkfish ranged from 0.37 to $1.81 \mu \mathrm{g} \mathrm{g}^{-1}$ wet wt in supermarkets and culture areas. Chen et al. (2000) also indicated that milkfish from culture ponds near scrap metal reclamation facilities are capable of accumulating metals such as $\mathrm{Cu}, \mathrm{Cd}, \mathrm{Al}$, and $\mathrm{Zn}$.

Milkfish culture needs a high amount $(38,000-49,000$ tons $\mathrm{ha}^{-1}$ ) of freshwater, and thus the fish in the ponds using groundwater may be contaminated with As. Arsenic can be accumulated in milkfish tissue, and people who consume these tissues may be threatened by As and lead to adverse health effects. Since milkfish is a common seafood in Taiwan, it is important to determine the As content in milkfish from culture ponds. The tolerance of milkfish to As toxicity as well as the As accumulation from the ambient water in the fish need to be determined. The process of accumulation of waterborne chemicals by fish and other aquatic animals through nondietary routes is defined as bioconcentration.

The bioconcentration factor (BCF), relating the concentration of a chemical in water to its concentration in the aquatic animal at steady-state, is generally used to estimate the propensity of an organism accumulating chemicals. Fish are targets for BCF assessments because of their importance as a human food source and the availability of standardized testing protocols. Measured or predicted $\mathrm{BCFs}$ are a requisite component for both environmental and human risk assessment (Liao and Ling, 2003). In this work, the bioaccumulation of As in milkfish was studied to assess the potential hazards of As in the aquaculture environment as well as human consumption risks. The acute toxicity of As and the $\mathrm{BCF}$ value of the milkfish were determined.

By using a deterministic risk analysis method to estimate target hazard quotients and potential health risks of metal exposure from consumption of seafood may hide significantly different levels of conservatism in relation to the uncertainty and variability present in each exposure parameter. Recently, probabilistic modeling has received increasing support as a promising technique for characterizing uncertainty and variation in exposure estimates to environmental contaminants. To date, however, only a limited number of risk assessments regarding aquacultural management have incorporated probabilistic analyses. Reinert et al. (1991) suggested that a predictive assessment is needed to evaluate the potential for As bioaccumulation, toxic effects to fish, and risks to human health.

The aim of this study is twofold: (1) to conduct an acute toxicity bioassay and an accumulation experiment to estimate the toxicokinetic and toxicodynamic parameters of milkfish exposed to As and (2) to evaluate the public health threat for both the fishers and non-fishers who consume As-contaminated milkfish from BFD area based on a probabilistic risk approach.

\section{Materials and methods}

\subsection{Accumulation experiment}

Samples of juvenile milkfish (average $24.95 \mathrm{~cm}$ in length and average $237.82 \mathrm{~g}$ in weight) and ambient water were obtained from nine culture ponds from four different farm sites of Putai, Yichu, Pemen, and Hsuehchia in BFD-endemic area.
Three fish and three $500 \mathrm{ml}$ water samples per pond were collected. The milkfish were placed on ice immediately, and kept at $4{ }^{\circ} \mathrm{C}$ during transfer to the laboratory. Water samples were fixed by adding $5 \mathrm{ml} 1 \mathrm{~N} \mathrm{HNO}_{3}$. A total of 80 non-contaminated milkfish (body length 4-6 cm) were collected from the Tainan Fisheries Research Institute for laboratory uptake/depuration experiments. The fish were transferred into 6 tanks of approximately 801 volume, containing 601 of filtered water. The temperature, $\mathrm{pH}$ and dissolved oxygen were maintained at $24.0 \pm 0.5^{\circ} \mathrm{C}$, $7.0 \pm 0.2$ and $8.0 \pm 0.1 \mu \mathrm{g} \mathrm{ml}^{-1}$, respectively; which were similar to the conditions of the culture ponds in BFD-endemic area $\left(24.0 \pm 3.2^{\circ} \mathrm{C}, 0,7.0 \pm 1.1\right.$ and $8.0 \pm$ $0.9 \mu \mathrm{g} \mathrm{ml}^{-1}$, respectively). The milkfish were held for 2 weeks before they were exposed to As.

Uptake and depuration assays of As were examined in two replicate aquaria and each aquarium was contained 50 fish. The sodium arsenite $\left(\mathrm{NaAsO}_{2}\right)$ stock solution was prepared with deionized water. The As level was determined by the median lethal tolerance (LT50) of milkfish at $\leq 5 \mathrm{mg} \mathrm{l}^{-1}$ As was longer than $14 \mathrm{~d}$. The milkfish were reared in the contaminated environment for $7 \mathrm{~d}$ uptake. We collected tested fish at the 0,1 st, 2nd, 3rd, 4th, and 7th day and took three fish to measure and remove in freezer until they were analyzed. Photoperiod was set to $12 \mathrm{~h}$ light: $12 \mathrm{~h}$ dark to mimic the natural photoperiod.

All the experiments were assigned to two replicate tanks. In order to maintain the ideal experimental condition, we removed the faeces every $3 \mathrm{~h}$ and collected forage debris $1 \mathrm{~h}$ after feeding. The whole As solution was replaced daily in each tank to avoid the regression of ambient water quality and keep the constant As concentration level. We checked the water level in each aquarium every $6 \mathrm{~h}$; if the water level dropped drastically, we supplied each aquarium with distilled water to keep a constant level.

We detected As concentrations in each test media, exposure water characteristics during the test were measured 3 times weekly in one selected replicated aquarium for analysis of As. The $10 \mathrm{ml}$ water samples were acidified $(\mathrm{pH}<1)$ with $5 \mathrm{ml} 1 \mathrm{~N} \mathrm{HNO}_{3}$ and then stored at $-4{ }^{\circ} \mathrm{C}$ in the dark until they were analyzed. No fish died during the acclimated period. No mortality occurred during the As exposures and no weight losses were observed.

Each removed fish was individually wrapped in a plastic bag and stored frozen. The dissected fish samples were cleaned with deionized water and were freeze-dried overnight, and then grounded to fine powder in a grinder (TaiHsiang S36-89, Taiwan). The resulting solution was evaporated and the residue redissolved in $0.1 \mathrm{~N} \mathrm{HCl}$.

\subsection{Acute toxicity bioassay}

Laboratory static bioassays were conducted to determine the $24,48,72,96$, 120, and 144-h LC50 values for milkfish exposed to As. The experimental design and calculations for the acute toxicity were based on well-known procedures given by Finney (1978) and Sparks (2000). The tests were carried out in 541 rectangular fiberglass aquaria with well-aerated and reconstituted dilution water $(\mathrm{pH} 7.8-8.0)$. The tested fish were collected from fish ponds in Taiwan Fisheries Research Institute, Lukang, Chunghwa. Eight healthy milkfish of a specific size class (mean body length $=5.1 \pm 1.2 \mathrm{~cm}$ and mean body weight $=1.34 \pm 0.8 \mathrm{~g}$ wet $\mathrm{wt}$ ) were randomly selected and transferred into each test aquarium. Dissolved oxygen in each tank was maintained at close to saturation by aeration $\left(7.95 \pm 0.03 \mu \mathrm{g} \mathrm{ml}^{-1}\right)$. The temperature in each aquarium was maintained at $24.3 \pm 3.2^{\circ} \mathrm{C}$ using submerged heaters.

The sodium arsenite $\left(\mathrm{NaAsO}_{2}\right)$ stock solution was prepared with deionized water. The fish were visibly free of any deformities, lesions or disease and acclimated in tap water for one week prior to experiment. The nominal concentrations of As were 0 (control), 5, 10, 15, 20, 25, 50, 100, 250, 500, and $1000 \mu \mathrm{g}$ $\mathrm{ml}^{-1}$. Gross mortality of fish to each concentration was recorded every $1 \mathrm{~h}$ for the first $12 \mathrm{~h}$ and every $2 \mathrm{~h}$ thereafter for $96 \mathrm{~h}$, and dead fish being removed every $1-2 \mathrm{~h}$. Milkfish were not fed throughout the test. Control and tested concentrations were measured in duplicate. The water quality management protocol was the same as deployed as the exposure experiments. No mortality occurred in the controls.

The LC50 values were determined from maximum likelihood estimates of linear functions relating log As concentration to probit transformations of percent mortality (Finney, 1978). The LC50 values were determined using mean assayed As concentrations and cumulative mortality. Statistical comparisons between LC50s were based on the standard error of the difference. When it became apparent no statistically significant differences in LC50s between bioassay replicates $(p>0.05)$, 
the replicates were pooled and a single LC50 was calculated for As. Chi-square tests were performed to test the homogeneity of mortality between replicates. The median lethal time (LT50) was also determined.

\subsection{Data analysis}

\subsubsection{Toxicokinetics}

We used a first-order one-compartment model to describe uptake and elimination processes of milkfish to As. The appropriate toxicokinetic parameters were estimated by fitting a first-order kinetic equation to the experimental data using non-linear regression analysis,

$C_{\mathrm{f}}(t)=C_{\mathrm{f}}(0) e^{-k_{2} t}+\frac{k_{1}}{k_{2}} C_{\mathrm{w}}\left(1-e^{-k_{2} t}\right)$,

where $C_{\mathrm{f}}$ is the As concentration in milkfish ( $\mu \mathrm{g} \mathrm{g}^{-1}$ dry wet), $C_{\mathrm{w}}$ is the dissolved As concentration in water $\left(\mathrm{mg} \mathrm{l}^{-1}\right), k_{1}$ is uptake rate constant $\left(\mathrm{ml} \mathrm{g}^{-1}\right.$ $\left.\mathrm{d}^{-1}\right)$ and $k_{2}$ is depuration rate constant $\left(\mathrm{d}^{-1}\right)$ of arsenic, and $t$ is time in days. The equilibrium bioconcentration factor $(\mathrm{BCF})$ can be calculated from the equation $\mathrm{BCF}=k_{1} / k_{2}$.

\subsubsection{Acute toxicity}

We used a parsimonious critical body residue (CBR) theory (Verhaar et al., 1999; Legierse et al., 1999) that assumes that the effect occurs when the total body burden of an organism reaches a certain threshold level, to link LC50(t), the median lethal time $\left(\operatorname{LT5} 5\left(C_{\mathrm{w}}\right)\right), \mathrm{BCF}$, and depuration rate constant $\left(k_{2}\right)$,

$\operatorname{LC} 50(t)=\frac{\mathrm{CBR}}{\operatorname{BCF}\left(1-e^{-k_{2} t}\right)}=\frac{\operatorname{LC} 50(\infty)}{1-e^{-k_{2} t}}$,

where $\mathrm{CBR}$ is critical burden residue defined as the threshold for $50 \%$ mortality ( $\mu \mathrm{g} \mathrm{g}^{-1}$ wet wt) and $\mathrm{LC} 50(\infty)=\mathrm{CBR} / \mathrm{BCF}$ is the incipient LC50 at infinite time $\left(\mu \mathrm{g} \mathrm{ml}^{-1}\right)$. The $\operatorname{LT50}\left(C_{\mathrm{w}}\right)$ for a given exposure concentration $C_{\mathrm{w}}$ can be derived directly from Eq. (2),

$\operatorname{LT50}\left(C_{\mathrm{w}}\right)=-k_{2}^{-1} \ln \left(1-\frac{\operatorname{LC} 50(\infty)}{C_{\mathrm{w}}}\right)$.

\subsubsection{Toxicodynamics: concentration-response model}

Whole-body residues and adjusted response frequencies were used to construct a concentration-response relationship for mortality effect versus steady-state As level in milkfish based on a three-parameter Hill equation model (Bourne, 1995). By fitting the Hill equation model to the observed mortality data recorded from acute toxicity bioassay, we can obtain a concentration-response profile based on an external effect concentration (EEC). We may appropriately transform the EEC-based concentration-response profile to an internal effect concentration (IEC)-based concentration-response model by a CBR concept as,

$M=\frac{100 \times C_{\mathrm{w}}^{n}}{(\operatorname{LC} 50)^{n}+C_{\mathrm{w}}^{n}}=\frac{100 \times C_{\mathrm{f}}^{n}}{(\operatorname{BCF} \times \operatorname{LC} 50(\infty))^{n}+C_{\mathrm{f}}^{n}}$,

where $M$ is the mortality (\%) and the exponent $n$ is a fitted average Hill coefficient.

\subsection{Chemical and statistical analysis}

Samples were sent to the Super Micro Mass Research and Technology Center, Cheng Shiu Institute of Technology for analysis of total As. The frozen muscle of milkfish was dehydrated in a dryer $\left(40^{\circ} \mathrm{C}\right)$ for $96 \mathrm{~h}$ and grounded into powder. Aliquots of dry muscle powder, weighing $0.5 \mathrm{~g}$, were placed into a $250 \mathrm{ml}$ beaker. Nitric acid $(65 \%, 10 \mathrm{ml})$ was added and then covered with a glass for an overnight digestion. After the initial digestion, the beaker was heated with a water bath at 70 $80{ }^{\circ} \mathrm{C}$ for $2-4 \mathrm{~h}$ to reduce the total volume to $1-2 \mathrm{ml}$. This volume of solution was transferred to a volumetric flask $(50 \mathrm{ml})$. The rinsed solution $(5 \mathrm{ml}$ of $0.01 \mathrm{~N}$ of $\mathrm{HNO}_{3}$ ) for the watch glass was also added to the flask. The flask was then filled with $0.01 \mathrm{~N}_{\text {of }} \mathrm{HNO}_{3}$ to make a $50 \mathrm{ml}$ of final solution and was transferred to test tubes for As analysis.
Arsenic analysis was carried out by using an Agilent 7500a ICP-MS. Analyzing quality control was achieved by digesting and analyzing identical amounts of rehydrated $\left(90 \% \mathrm{H}_{2} \mathrm{O}\right)$ standard reference material (DORM-2, Dogfish Liver-2-organic matrix, NRC-CNRC, Canada). Recovery rates ranged from $95 \%$ to $97 \%$. We employed the nonlinear option of Statistica software (StatSoft, Tulsa, OK) to perform all curve fittings. Statistica software was also used to calculate the coefficient of determination $\left(r^{2}\right)$ and statistical analyses (analysis of variance and Student's $t$ test). Statistical significance was determined at $p<0.05$.

\subsection{Risk analysis}

\subsubsection{Risk effect of As on milkfish}

Risk at a specific As concentration in whole-body milkfish $\left(C_{\mathrm{f}}\right)$ can be calculated as the proportion of the milkfish expected to have that tissue concentration multiplied by the conditional probability of milkfish mortality, given concentration $C_{\mathrm{f}}$. This results in a joint probability function (JPF) or exceedence profile, which describes the probability of exceeding the concentration associated with a particular degree of effect. This can be expressed mathematically as

$R \equiv F\left(C_{\mathrm{f}}\right) \times F\left(M \mid C_{\mathrm{f}}\right)$,

where $R$ is the risk for whole-body milkfish at concentration $C_{\mathrm{f}}, F\left(C_{\mathrm{f}}\right)$ is the cumulative distribution function (cdf) of having tissue concentration $C_{\mathrm{f}}$, and $F\left(M \mid C_{\mathrm{f}}\right)$ is the conditional cdf of a predicted mortality function for a given tissue As concentration $C_{\mathrm{f}}$ based on Eq. (4), and could be expressed symbolically as

$F\left(M \mid C_{\mathrm{f}}\right)=\Phi\left(\frac{100 \times C_{\mathrm{f}}^{n}}{(\mathrm{BCF} \times \operatorname{LC} 50(\infty))^{n}+C_{\mathrm{f}}^{n}}\right)$,

where $\Phi(\bullet)$ is the cumulative standard normal distribution. We treated BCF and $\operatorname{LC} 50(\infty)$ in Eq. (6) probabilistically.

\subsubsection{Human health exposure and risk model}

The target cancer risk to adults can be defined by using the incremental lifetime cancer risk (ILCR) for incidental exposure to inorganic As as,

$\mathrm{TR}=\frac{D_{\mathrm{f}} \times\left(\mathrm{CSF}_{\mathrm{IRIS}}\left(\frac{\mathrm{BW}}{70 \mathrm{~kg}}\right)^{1 / 3}\right) \times \mathrm{IR}_{\mathrm{f}} \times \mathrm{EF} \times \mathrm{ED}}{\mathrm{BW} \times \mathrm{AT}_{\mathrm{c}} \times 10^{3}}$,

where TR is the incremental individual lifetime cancer risk (dimensionless), $C_{\mathrm{f}}$ is the As concentration in fish $\left(\mu \mathrm{g} \mathrm{g}^{-1}\right), \mathrm{CSF}_{\text {IRIS }}$ is the oral carcinogenic slope factor for inorganic As from IRIS (Integrated Risk Information System, provided by US EPA) database $(\mathrm{mg} / \mathrm{kg} / \mathrm{d})^{-1}, I_{\mathrm{f}}$ is the annualized fish ingestion rate $\left(\mathrm{g} \mathrm{d}^{-1}\right), \mathrm{EF}$ is the exposure frequency $\left(\mathrm{d} \mathrm{yr}^{-1}\right), \mathrm{ED}$ is the exposure duration (yr), BW is the body weight $(\mathrm{kg}), \mathrm{AT}_{\mathrm{c}}$ is the averaging time for carcinogens (d) and $10^{3}$ is the unit conversion factor.

The noncancer risk was estimated using the hazard quotient approach, defined as,

$\mathrm{HQ}=\frac{C_{\mathrm{f}} \times \mathrm{IR}_{\mathrm{f}} \times \mathrm{EF} \times \mathrm{ED}}{\left(\operatorname{RfD}_{\mathrm{IRIS}}\left(\frac{\mathrm{BW}}{70 \mathrm{~kg}}\right)^{1 / 3}\right) \times \mathrm{BW} \times \mathrm{AT}_{\mathrm{nc}} \times 10^{3}}$,

where HQ is the toxicity hazard quotient (dimensionless), $\mathrm{RfD}_{\text {IRIS }}$ is the oral reference dose from IRIS database $\left(\mathrm{mg} \mathrm{kg}^{-1} \mathrm{~d}^{-1}\right), \mathrm{AT}_{\mathrm{nc}}$ is the averaging time for noncarcinogens (d), and $10^{3}$ is the unit conversion factor. We treated $\mathrm{BW}, C_{\mathrm{f}}$ and $\mathrm{IR}_{\mathrm{f}}$ in Eqs. (7) and (8) probabilistically.

Donohue and Abernathy (1999) reported that the amount of inorganic As in seafood ranges from $<3 \%$ to $7 \%$ of the total As. In this work, it is assumed that inorganic As accounts for $5 \%$ of the total As in milkfish. The exposure duration is defined as the exposure frequency of $365 \mathrm{~d} \mathrm{yr}^{-1}$ for $30 \mathrm{yr}$ (i.e., 10,950 d). The averaging time and number of fish consumed are required to provide input for an estimate of human health risk from exposure through fish ingestion. An averaging time of $365 \mathrm{~d} \mathrm{yr}^{-1}$ for $70 \mathrm{yr}$ (i.e., $\mathrm{AT}_{\mathrm{c}}=25,550 \mathrm{~d}$ ) was used to characterize lifetime exposure for cancer risk calculation. An averaging time of 
$365 \mathrm{~d} \mathrm{yr}^{-1}$ for $30 \mathrm{yr}$ (i.e., $\mathrm{AT}_{\mathrm{nc}}=10,950 \mathrm{~d}$ ) was used in characterizing noncancer risk.

The cancer slope factor and reference dose for ingested inorganic arsenic are $1.50\left(\mathrm{mg} \mathrm{kg}^{-1} \mathrm{~d}^{-1}\right)^{-1}$ and $3 \times 10^{-4} \mathrm{mg} \mathrm{kg}^{-1} \mathrm{~d}^{-1}$, respectively, provided by US EPA IRIS database (http://www.epa.gov/iris) and normalized to account for extrapolation to a different body weight from the standard of $70 \mathrm{~kg}$ (Eqs. (7) and (8)), as suggested in the Exposure Factors Handbook (USEPA, 1997). These values are specified as point estimates following US EPA guidance (USEPA, 1989a). It was assumed in accordance with the US EPA (USEPA, 1989b) guideline that the ingested dose is equal to the absorbed contaminated dose and that cooking has no effect on the contaminants. The acceptable risk distribution was assigned by constraints on percentiles. The lower end of the range of acceptable risk distribution is defined by a single constraint on the $90 \%$-tile of risk distribution that must be equal or lower than $10^{-6}$ for carcinogens and equal or lower than 1 for noncarcinogens.

\subsection{Uncertainty analysis}

\subsubsection{Model parameterization}

Parameterization of the model involved selecting data sets and deriving input distributions. Current literature was reviewed to develop probability distributions for the random variables appearing in the human health exposure and risk model adopted. Absolute and relative frequencies were calculated, and distributions were plotted using bin midpoints. The $\chi^{2}$ and Kolmogorov-Smirnov $(\mathrm{K}-\mathrm{S})$ statistics were used to optimize the goodness of fit of distributions. The selected distribution type and parameters were based on statistical criteria and comparisons of distribution parameters. The implemented parameter probability distributions are summarized in Table 1 and described in the subsequent sections.

2.6.1.1. Toxicokinetic parameter: $B C F$. In applying toxicokinetic relationship derived from experimental study, we must consider the limitations of the data and account for the inherent uncertainty that arises from a number of sources, including the limited number of observations and limited sample size within treatment sets. To account for this uncertainty, the distribution for the input variable of $\mathrm{BCF}$ was derived from the relationship of $\mathrm{BCF}=C_{\mathrm{f}} / C_{\mathrm{w}}$. Lognormal (LN) distributions for $\mathrm{BCF}$ in four different milkfish farm sites were determined (Table 1 and Fig. 1).

2.6.1.2. Geochemical parameter: $C_{w}$. Distributions of water As concentrations in milkfish ponds $\left(C_{\mathrm{w}}\right)$ were fit to the polled field observations obtained from nine assigned milkfish farms from Putai, Hsuehchia, Peman, and Yichu in $\mathrm{BFD}$-endemic area and the selected lognormal distributions had the optimal $\mathrm{K}-\mathrm{S}$ and $\chi^{2}$ goodness-of-fit (Table 1 and Fig. 1).

2.6.1.3. Parameter in Hill model: LC50( $\infty)$. We determined a truncated normal (TN) distributions for LC50( $\infty)$ (Table 1), and incorporated the distributions into the Monte Carlo simulation to obtain 2.5\%- and 97.5\%-tiles as the $95 \%$ CI for reconstructed concentration-response profile. Uncertainty and/or variability were not considered for the reported Hill coefficient since the Hill coefficient from the published study was reported only as an average value.

2.6.1.4. Human health exposure/risk model parameters: $C_{f}, B W, I R_{f}$. Data on milkfish consumption patterns were adopted from two sources: (1) Fisheries Statistical Year Book (2003), which was estimated by dividing the annual consumption quantities of milkfish in the BFD-endemic area and (2) Lin (Nanhua University, Chiayi, Taiwan, ROC, unpublished work), which was based on a brief questionnaire on milkfish daily consumption rate for 141 subsistence fishers in BFD-endemic area. Lin (unpublished work) provided data on milkfish daily consumption rates for non-fishers in BFD-endemic area: $16.8-50.05$ and 29.4$59.15 \mathrm{~g} \mathrm{~d}^{-1}$ for 2-6 and 7-14 meals per week. The edible percentage of farmed milkfish is $35 \%$ suggested by Lung et al. (2003). We approximated these data using a lognormal distribution and transformed appropriately to ensure the data did not differ from a normal distribution before parametric analysis. Results give milkfish consumption rate distributions of $\mathrm{LN}\left(194.53 \mathrm{~g} \mathrm{~d}^{-1}, 2.66\right)$ for fishers and $\mathrm{LN}\left(6.44 \mathrm{~g} \mathrm{~d}^{-1}, 1.33\right)$ for non-fishers. Distribution of the average weight of Taiwanese adults was fitted to the data obtained from Department of Health, Taiwan (http://www.doh.gov.tw) (ages range from 19 to 65 years) and the selected truncated normal (TN) distribution had the optimal K-S goodness-of-fit (Table 1).
Table 1

Fitted lognormal (LN) and truncated normal (TN) distributions of input variables for Monte Carlo simulations

\begin{tabular}{|c|c|c|c|}
\hline Parameters & Symbol & $\begin{array}{l}\text { Uncertainty/ } \\
\text { variability }\end{array}$ & Value \\
\hline \multicolumn{4}{|l|}{ Toxicokinetic parameter } \\
\hline \multirow{5}{*}{$\begin{array}{l}\text { Site-specific } \\
\text { bioconcentration } \\
\text { factor for milkfish }\end{array}$} & $\mathrm{BCF}\left(\mathrm{ml} \mathrm{g}^{-1}\right)$ & $\mathrm{U}$ & \\
\hline & Putai & & $\mathrm{LN}(12.43,1.81)$ \\
\hline & Hsuehchia & & $\mathrm{LN}(10.36,1.41)$ \\
\hline & Pemen & & $\operatorname{LN}(10.31,1.46)$ \\
\hline & Yichu & & $\operatorname{LN}(4.09,1.41)$ \\
\hline \multicolumn{4}{|c|}{ Geochemical parameter } \\
\hline \multirow{5}{*}{$\begin{array}{l}\text { Site-specific } \\
\text { dissolved arsenic } \\
\text { concentration in } \\
\text { water }\end{array}$} & $C_{\mathrm{w}}\left(\mathrm{mg} \mathrm{l}^{-1}\right)$ & $\mathrm{U}$ & \\
\hline & Putai & & $\mathrm{LN}(0.00105,1.11)$ \\
\hline & Hsuehchia & & $\mathrm{LN}(0.00150,1.28)$ \\
\hline & Pemen & & LN $(1.00160,1.16)$ \\
\hline & Yichu & & $\mathrm{LN}(0.00475,1.06)$ \\
\hline \multicolumn{4}{|c|}{ Concentration-response parameter } \\
\hline $\begin{array}{l}\text { Incipient median } \\
\text { lethal concentration }\end{array}$ & $\operatorname{LC} 50(\infty)\left(\mathrm{mg} \mathrm{l}^{-1}\right)$ & $\mathrm{U}$ & $\mathrm{TN}(8.45,2.52)$ \\
\hline \multicolumn{4}{|c|}{ Human health risk parameter } \\
\hline \multirow{3}{*}{$\begin{array}{l}\text { Human milkfish } \\
\text { ingestion rate }\end{array}$} & $\mathrm{IR}_{\mathrm{f}}\left(\mathrm{g} \mathrm{d}^{-1}\right)$ & $\mathrm{U} / \mathrm{V}$ & \\
\hline & Fisher & & $\mathrm{LN}(194.53,2.66)$ \\
\hline & Non-fisher & & $\mathrm{LN}(6.44,1.33)$ \\
\hline $\begin{array}{l}\text { Body weight of } \\
\text { Taiwanese adults }\end{array}$ & $\mathrm{BW}(\mathrm{kg})$ & $\mathrm{V}$ & $\mathrm{TN}(59.92,4.36)$ \\
\hline
\end{tabular}

\subsubsection{Monte Carlo analysis}

In order to quantify this uncertainty and its impact on the estimation of expected risk, we implemented a Monte Carlo simulation that includes input distributions for the parameters of the derived dose-response function as well as for estimated exposure parameters. To test the convergence and the stability of the numerical output, we performed independent runs at $1,4,5$ and 10 thousand iterations with each parameter sampled independently from the appropriate distribution at the start of each replicate. Largely because of limitations in the data used to derive model parameters, inputs were assumed to be independent. The result shows that 10,000 iterations are sufficient to ensure the stability of results. We performed a sensitivity analysis to identify the most significant parameters that were included in the uncertainty and variability analysis. We assessed the sensitivity of each variable relative to one another by calculating rank correlation coefficients between each input and output during simulations and then estimated each input contribution to the output variance by squaring the output variance and normalizing to $100 \%$. The model parameterization, the Monte Carlo simulation and sensitivity analysis were implemented using Crystal Ball ${ }^{\circledR}$ software (Version 2000.2, Decisioneering, Inc., Denver, Colorado, USA).

\section{Results}

\subsection{Toxicokinetic parameters and LC50(t) data}

The 7-d exposure experiment of As in whole-body of milkfish had significant correlated with nonlinear regression profile $\left(r^{2}=0.98, p<\right.$ $0.05)$ resulting from the best fit of the first-order one-compartment uptake-depuration model (Fig. 2). The uptake rate constant $\left(k_{1}\right)$ the depuration rate constant $\left(k_{2}\right)$ are estimated to be $0.31 \pm 0.08 \mathrm{ml} \mathrm{g}^{-1} \mathrm{~d}^{-1}$ and $0.25 \pm 0.18 \mathrm{~d}^{-1}$, respectively. Based on the study on the toxicity of As on tilapia (Oreochromis mossambicus), BCF is estimated to be $2.68 \pm$ $1.12 \mathrm{ml} \mathrm{g}^{-1}$ from a laboratory exposure experiment (Tsai and Liao, 

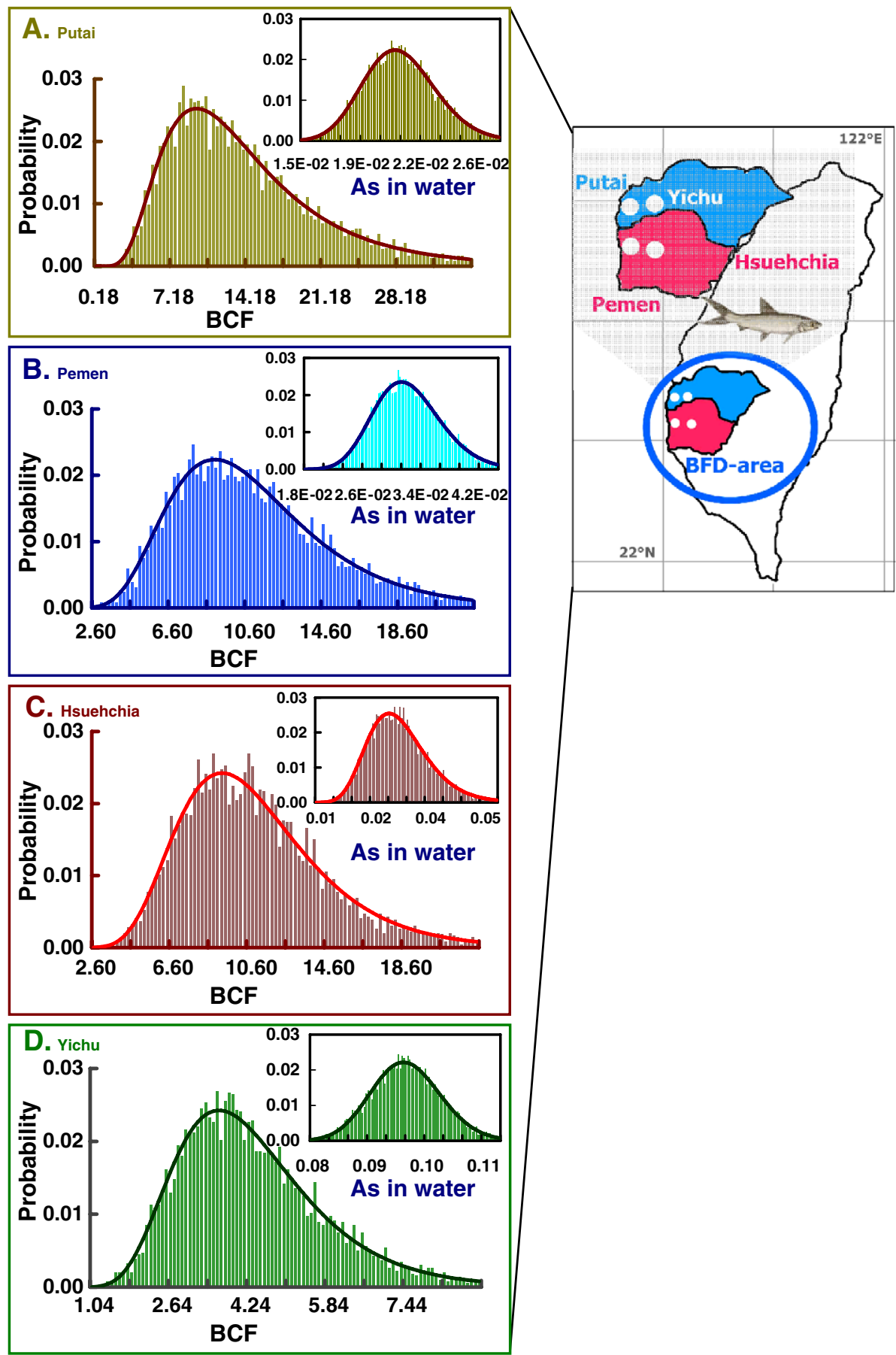

Fig. 1. Site-specific probability distributions of bioaccumulation factor (BCF) and As concentration in pond water for four selected milkfish farms located at (A) Putai, (B) Pemen, (C) Hsuehchia, and (D) Yichu in BFD-endemic area of Taiwan.

2006). In the present study, the estimated average BCF of whole-body milkfish is 1.24 that falls within the range of $2.68 \pm 1.12 \mathrm{ml} \mathrm{g}^{-1}$, indicating a comparable value. The depuration half-life $\left(t_{1 / 2}=\ln 2 / k_{2}\right)$ is calculated to be $2.77 \mathrm{~d}$, indicating that it will take a shorter time to eliminate As. According to the perspective of toxicology, if the contaminants stay in the tissue longer, there would be higher opportunity to cause adverse effect on that organism. These toxicokinetic parameters not only can be used to describe the uptake and depuration ability of milkfish but also can be further used to predict the concentration-response relationships between mortality and steady-sate As levels in water or in milkfish.
The selected time intervals of 24, 48, 72, and 96-h LC50 values with 95\% CI of As to milkfish are given in Table 2. LC50 value lowers smoothly as the duration of exposure increases. A limited number of studies have investigated As toxicity to milkfish. Our 96-h LC50s of As to milkfish is 7.29 (95\% CI: $3.10-10.47) \mathrm{mg}^{-1}$.

\subsection{Fitting CBR model to LC50(t) data and concentration-response profile}

The optimal fits of the CBR model to the LC50(t) data listed in Table 2 are presented in Fig. 3A. The input parameters used are whole- 


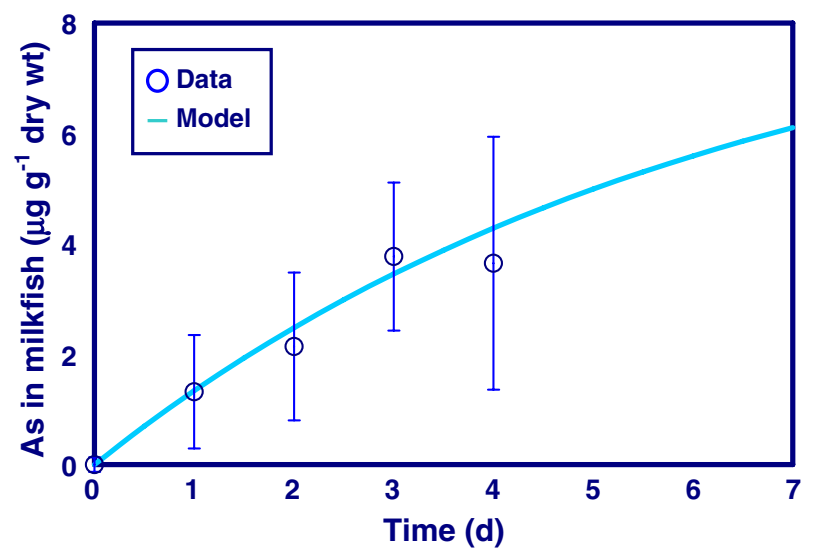

Fig. 2. Exposure experiment of juvenile milkfish Chanos chanos exposed to $1 \mathrm{mg}$ $1^{-1}$ As for 7 -d uptake. Data are mean with standard deviation $(n=6)$ and the solid line is best-fit regression curve from one-compartment kinetic model.

body mean $k_{2}=0.25 \mathrm{~d}^{-1}$. The estimated values for $\operatorname{LC} 50(\infty)$ is $8.45 \pm$ 2.52 (mean $\pm \mathrm{sd}) \mathrm{mg} \mathrm{l}^{-1}$. The coefficients of determination $\left(r^{2}\right)$ indicates that the quality of fitness for the CBR toxicity model $\left(r^{2}=0.91, p<0.05\right)$. Fig. 3B shows the relationships between LT50 and As level in water.

A concentration-response relationship between mortality and waterborne As concentration was derived using three-parameter Hill equation model (Eq. (4)) by nonlinear regression (Fig. 3C). The optimal fits of Eq. (4) to the observed percent mortality of milkfish versus waterborne As concentration of the 96-h acute toxicity test results in the estimated Hill coefficient, $n=2.02\left(r^{2}=0.96, p<0.05\right)$.

\subsection{Risk estimates of As on milkfish}

Fig. 4 shows the box plots of interquartile and 50\%-tile predictions associated with whisker plots indicating 10\%- and 90\%-tile predictions of As contents in whole-body milkfish in selected farms. The comparison of $90 \%$-tile values of pdfs showed that milkfish exposure to As caused the relative skewness and spread in modeled output varied among selected milkfish farms. Compared with the field observations (Fig. 4), measured As contents in milkfish were generally within the predicted $10 \%$ - to $90 \%$-tiles. Thus, applying the Monte Carlo technique to the proposed probabilistic bioaccumulation model generated probabilistic estimates of As concentration in milkfish were in a good agreement with field data. It is evident that the modeling framework and the distributional parameters and assumptions in the model are appropriate for estimating As bioaccumulation in farmed milkfish.

The site-specific concentration-response relationships between mortality and As level in milkfish were constructed based on the Hill equation model (Eq. (4)) and a 10,000 iteration of Monte Carlo simulation provided a knowledgeable uncertainty of $95 \%$ CI (Fig. 5). It can be seen from Fig. 5

Table 2

LC50 values (mean and 95\% CI) for selected time intervals for milkfish exposed to As

\begin{tabular}{llll}
\hline Time $(\mathrm{h})$ & Mean $\left(\mu \mathrm{g} \mathrm{ml}^{-1}\right)$ & \multicolumn{2}{l}{$95 \%$ confidence interval } \\
\cline { 3 - 4 } & & Lower & Upper \\
\hline 24 & 11.16 & 5.45 & 16.89 \\
48 & 8.12 & 3.03 & 12.35 \\
72 & 7.51 & 2.95 & 11.04 \\
96 & 7.29 & 3.10 & 10.47 \\
\hline
\end{tabular}
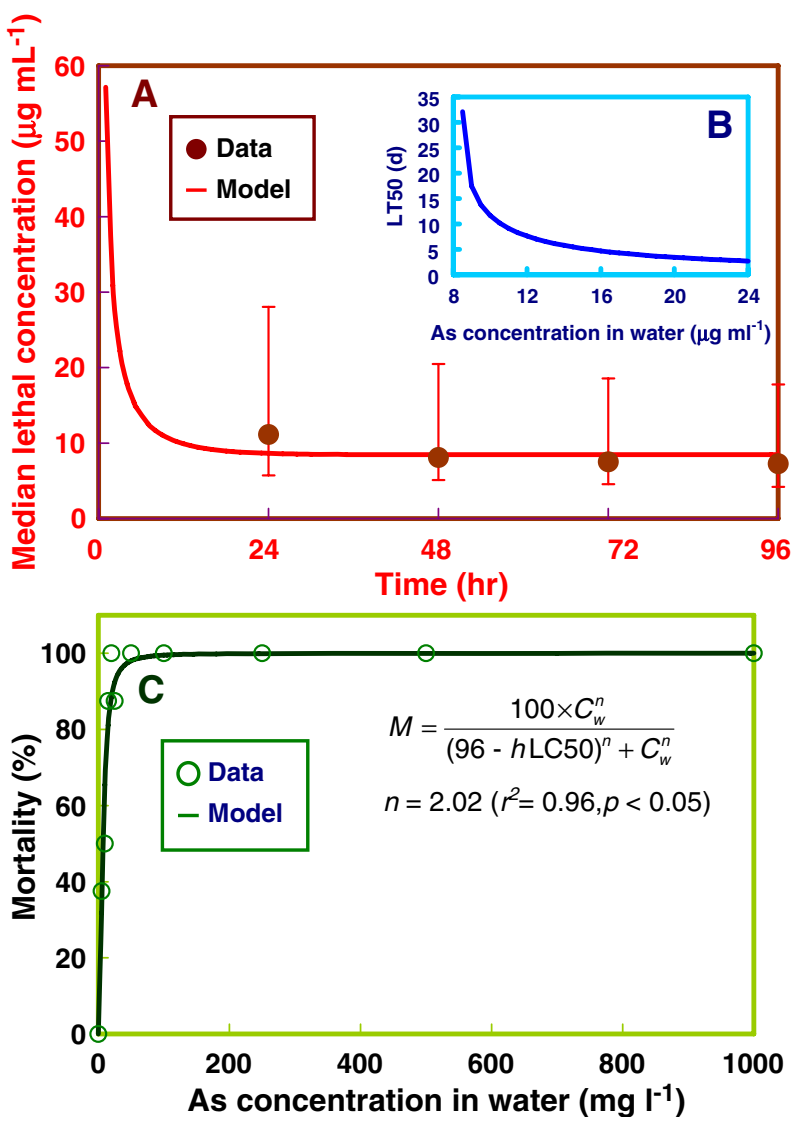

Fig. 3. (A) Optimal fit of CBR-based acute toxicity model to the LC50(t) data (mean $\pm 95 \%$ CI) listed in Table 2, (B) median lethal time as a function of water As concentration, and (C) optimal fit of three-parameter Hill equation model to observed percent mortality of milkfish versus waterborne As concentrations in the $96-\mathrm{h}$ acute toxicity bioassay.

that the calculated effective concentrations, inducing $10 \%$ mortality (EC10) values, are 34.46 (5.11-153.9) (median with 95\% CI), 29.38 (5.87-91.97), 29.36 (5.58-97.95), and 11.62 (2.38-36.03) for Putai,

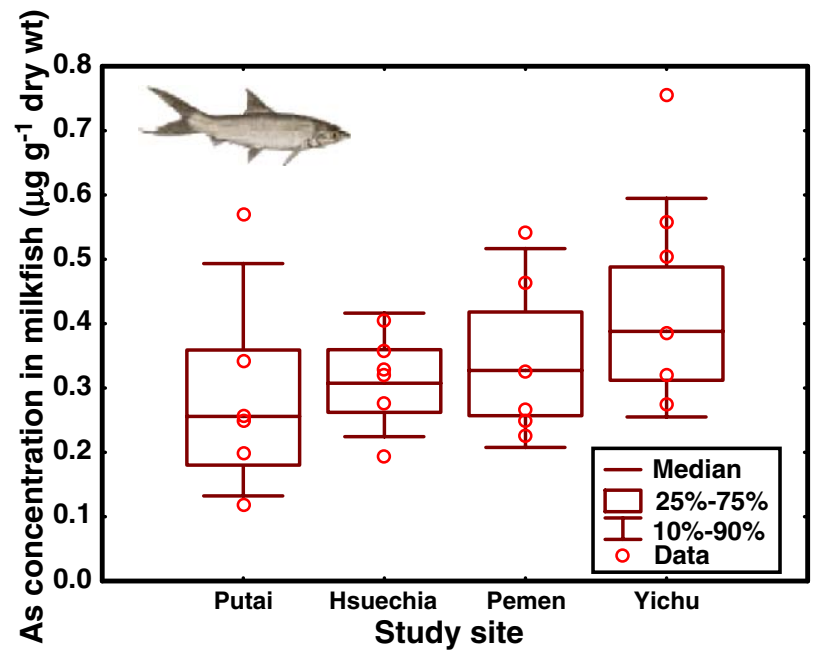

Fig. 4. Box-and-whisker plot representations of distributions of As concentration in milkfish. Box-and-whisker plots are used to represent the uncertainty in As level estimates. 
Hsuehchia, Pemen, and Yichu, respectively, based on fitted concentration-response model. USEPA (2000) recommended that EC10 could be used as a surrogate threshold of regulatory endpoint in probabilistic ecological risk assessment. The distributions of As concentration in milkfish below the threshold values of derived EC10 (Fig. 4), suggesting that waterborne As does not appear to pose a significant survival risk to farmed milkfish under field conditions at current environmental concentrations.

The As risk on milkfish can be defined as the percentage of the farmed milkfish that is expected to suffer mortality. Site-specific risk curves (Fig. 6) indicate the estimated probabilistic of effects for wholebody milkfish. The plotted probabilities calculated from the outcome of the Monte Carlo simulation followed a JPF (Eq. (5)) describing the exceedence cumulative probability associated with a particular degree of effect (Fig. 6), take into account the uncertainty in model parameters. Fig. 6 demonstrates that the probabilities that $10 \%$ or more of the milkfish (risk $=0.10)$ affected ranged from $1.87 \times 10^{-3} \%$ to $2.98 \times 10^{-3} \%$ for Putai, Hsuehchia, and Pemen, whereas $2.6 \times 10^{-3} \%$ for Yichu. Our results thus indicate that the probability is $10 \%$ that only $10^{-3}-10^{-2} \%$ of milkfish tissue will be damaged, suggesting no significant adverse effect for milkfish exposed to waterborne As from selected milkfish farms in BFD area.

\subsection{Human health risk estimates}

We used box-and-whisker plot to represent the uncertainty in comparing ILCRs and HQs, for box plots of interquartile and 50\%-tile predictions associated with whisker plots indicating $10 \%$ - and $90 \%$-tile values for varied human consumption of farmed milkfish by subsistence
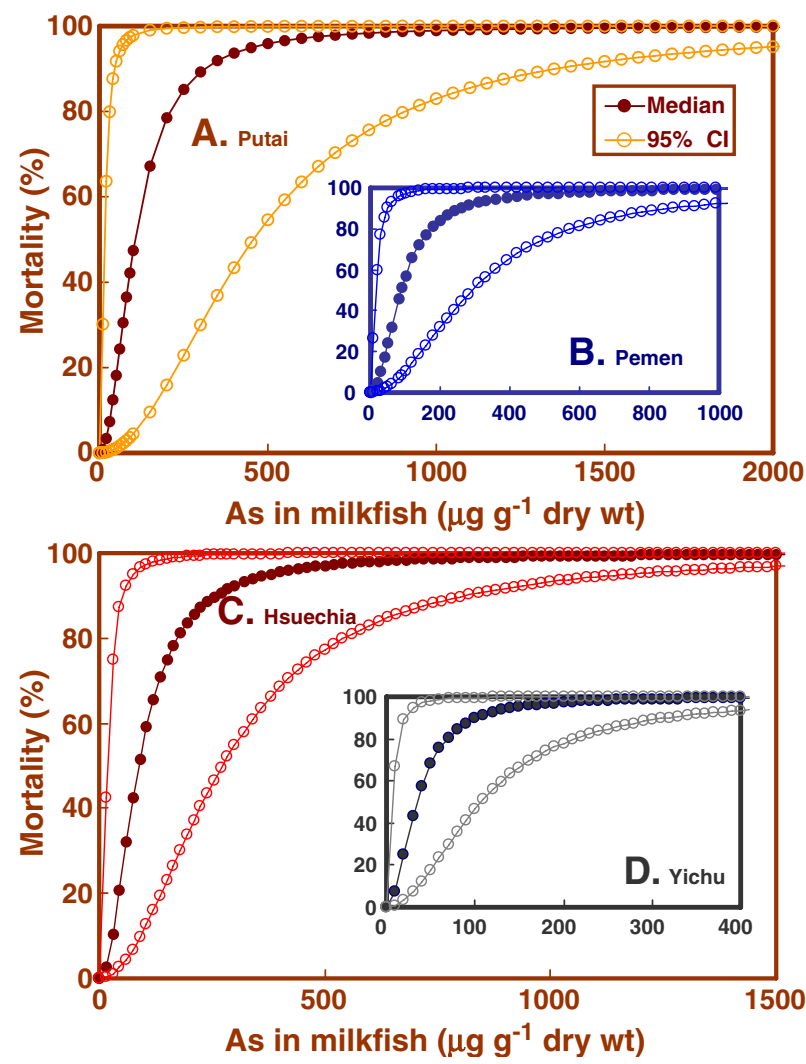

Fig. 5. Reconstructed site-specific concentration-response profiles with 95\% CI by a Hill equation model showing the relationships between milkfish mortality and As contents in milkfish.

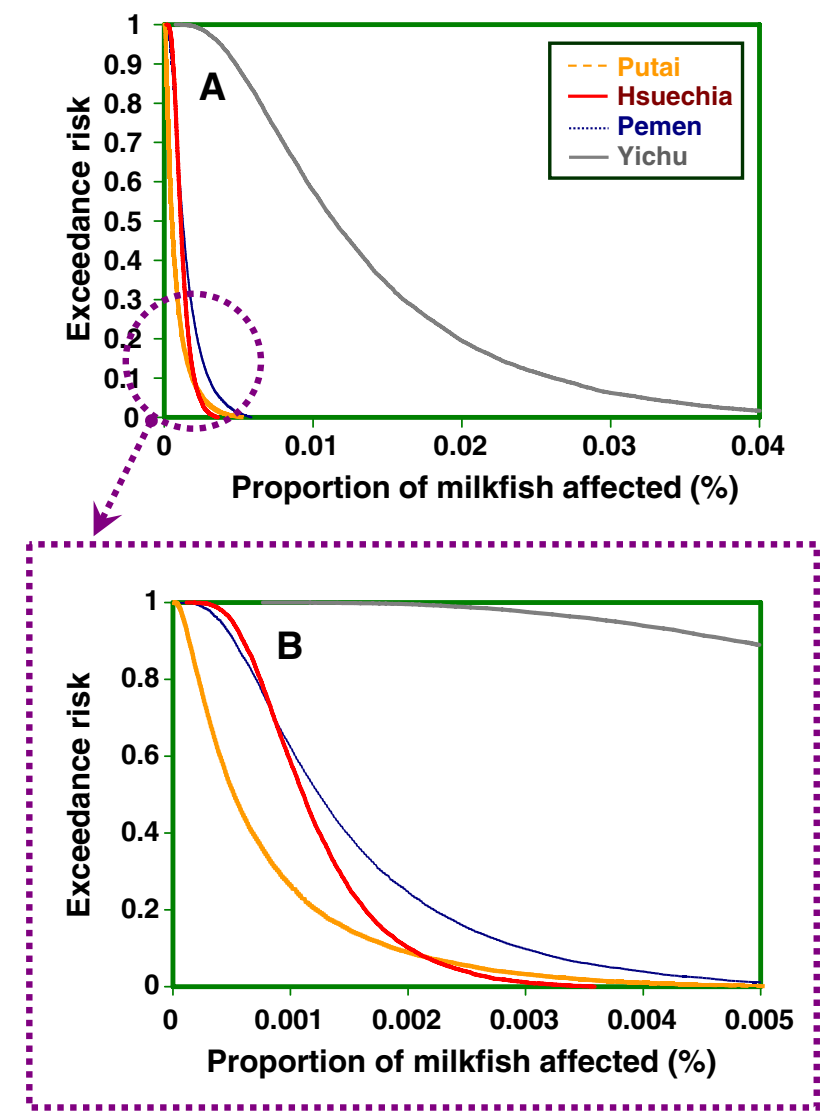

Fig. 6. Exceedence risk (mortality) for milkfish from four selected milkfish farms of Putai, Hsuehchia, Pemen, and Yichu in BFD-endemic area.

fishers and non-fishers, respectively (Fig. 7A and B). Under most regulatory programs, a HQ exceeding 1 and a ILCR between $10^{-4}$ and $10^{-6}$ indicate potential risk. Fig. 7A shows that for four selected milkfish farms, the probability distributions of fishers all experience a $25 \%-$ $90 \%$-tile of ILCR fell outside the range of $10^{-6}-10^{-4}$ with a median daily consumption rate of $194 \mathrm{~g} \mathrm{~d}^{-1}$, indicating high potential cancer risks associated with inorganic As uptake from milkfish. For non-fishers in BFD-endemic area, probabilities of ILCR fell within the range of $10^{-6}-10^{-5}$ with a median consumption rate of $6 \mathrm{~g} \mathrm{~d}^{-1}$, indicating insignificant health risks (Fig. 7A). For predicted HQ distributions (Fig. 7B), 90\%-tile HQ $<1(0.279-0.384)$ for non-fisher in four selected milkfish farms in BFD-endemic area, suggesting small contributions from milkfish consumption, whereas for subsistence fishers, all $90 \%$-tile HQ $>1$ (18-23.4), indicating significant contributions from milkfish consumption. The result of sensitivity analysis on human exposure model reveals that milkfish daily consumption rate and As level in milkfish are most sensitive to ILCR (78\%) and HQ (75\%).

\section{Discussion}

\subsection{Toxicokinetics/toxicodynamics of As for milkfish}

Because few previous studies have evaluated As toxicity to milkfish, we did not have an a priori estimate of internal lethal body burdens. Mechanisms of As toxicity in milkfish have not been investigated extensively. Several studies have reported acute toxicity of As to other fish species. Our result of the 96-h LC50 As 

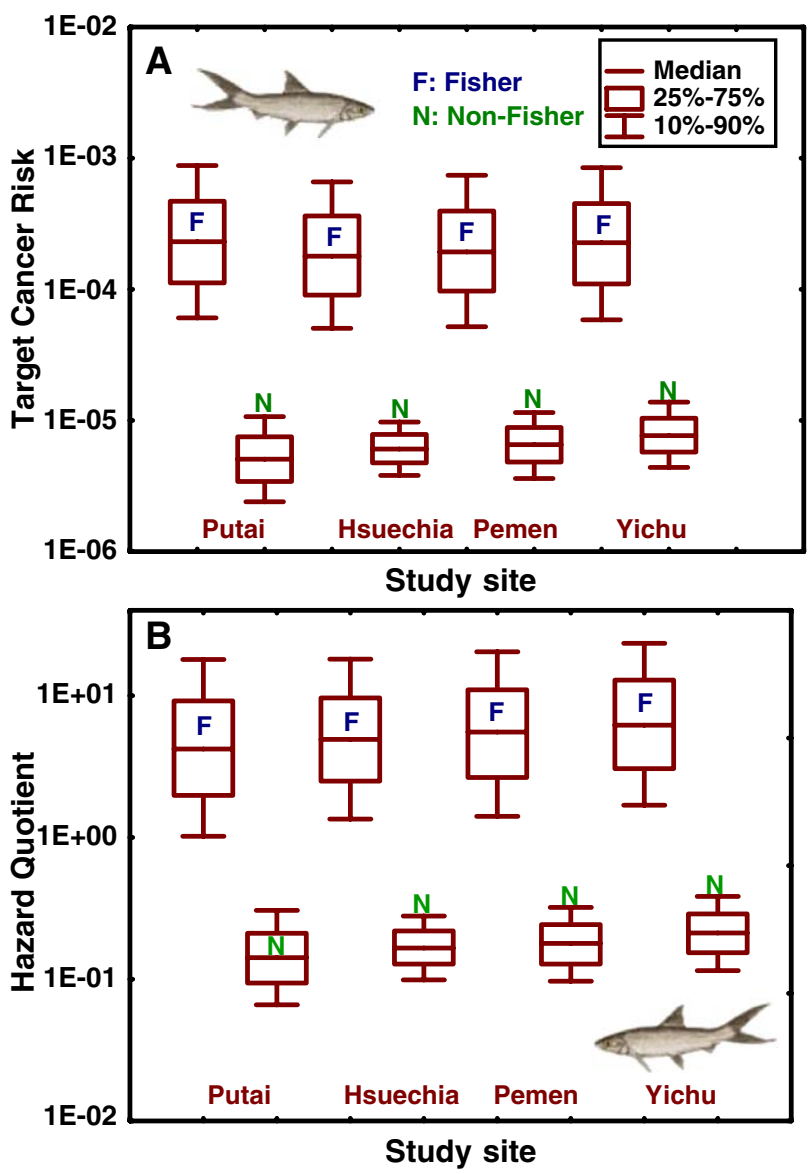

Fig. 7. Box-and-whisker plot representations of (A) target cancer risks and (B) hazard quotients for fishers and non-fishers living in four selected study sites of Putai, Hsuehchia, Pemen, and Yichu in BFD-endemic area.

( $95 \%$ CI: $3.10-10.47 \mathrm{mg} \mathrm{l}^{-1}$ ) for milkfish is much lower than the range of 96-h LC50 As to rainbow trout Oncorhynchus mykiss (23-26.6 $\mathrm{mg} \mathrm{l}^{-1}$ ) (Spehar et al., 1980), to bluegill Lepomis macrochirus (29-35 $\mathrm{mg} \mathrm{l}^{-1}$ ) (Johnson and Finley, 1980), and to tilapia Oreochromis mossambicus (24.92-32.44 $\mathrm{mg}^{-1}$ ) (Liao et al., 2003).

The mechanisms of As toxicity to milkfish are still limited in literature. We linked the refined three-parameter Hill equation model that used in pharmacology with a simple CBR toxicity model to assess the site-specific concentration-response relationships. The fit of the CBR toxicity model may be strongly determined by the input parameters. Therefore, uncertainties in the $k_{2}$ value, which is input parameter in the CBR toxicity model, affect the validation of the model. Generally, the experimental LC50(t $t)$ data for milkfish exposed to waterborne As support the validity of the CBR toxicity model $\left(r^{2}=0.91, p<0.05\right)$, despite the $k_{2}$ was estimated from 7-d exposure test in $1 \mathrm{mg} \mathrm{l}^{-1}$ As solution. Hermens (1989) and McCarty and Mackay (1993) also suggested that the concept of the whole body burden might not hold for chemicals exhibiting an irreversible adverse effect. A specific model of action, however, could also be complicated and misleading in estimating ecosystem concentrations and comparing these concentrations with LC50 data. McCarty and Mackay (1993) also pointed out that the constant whole body burden with respect to time and species for chemicals indicating the same mode of action.

Our work uses the CBR toxicity concept to derive the internal effect concentration-time response relationships for milkfish under a specific waterborne As exposure, which can also be applied to time-mortality data, and estimated toxicological parameters from the results in the traditional bioassay. Our results suggest the applicability of the CBR toxicity concept associated with a one-compartment first-order toxicokinetic model can describe and predict the time course of As toxicity to milkfish.

We employed a receptor theory-based pharmacodynamic model, based on Hill equation, to reconstruct site-specific concentration-response relationships between equilibrium As concentration in milkfish and their mortality effects. Therefore, the complete concentration-response profiles and duration of effect can be predicted for aquatic biota exposed to any waterborne metal. In order to obtain accurate and precise parameter estimates for $E_{\max }, \mathrm{EC} 50$ and $n$, the observation of effects have to include comprehensive ranges of concentrations (i.e., if $C<\mathrm{EC} 50$ ), then $E_{\max }$ or EC50 will not be a proper estimate (Derendorf and Hochhaas, 1995) and the fitted $n$ value will not be estimated accurately. The 96-h acute toxicity bioassay data obviously provided a suitable range for parameter estimations and site-specific concentration-response relationships predictions (Fig. 3C). We therefore suggest that we may employ the derived internal effect concentrations and whole-body concentration in the site-specific risk assessment. We further suggest that replacing exposure-based external effect concentrations by internal effect concentrations is an effective means to measure inherent toxicity.

\subsection{Implications from risk assessment}

We specifically chose to quantify adverse effects related to As exposure because the weight of available data including exposure and toxicological data from experimental studies strongly supports the choice of As as our study metalloid to carry out the risk assessment. Our proposed probabilistic methods show that field data or experimentally derived parameters may hide significantly different levels of conservatism in relation to the uncertainty and variability present in each input parameters. Variability and uncertainty in model inputs were addressed using conservative assumptions, a range of milkfish farm scenarios, and probabilistic analysis.

It is appropriate to apply a human health exposure risk model to account the HQ and ILCR for humans consuming contaminated milkfish. It was assumed that people only consumed the milkfish muscle. The ILCRs for both fishers and non-fishers in BFDendemic area are unacceptable, because the $90 \%$-tile exceeds $10^{-6}$, indicating potential health risks associated with inorganic As uptake from milkfish, i.e., the carcinogenic effects (inorganic As) for subsistence fishers and non-fisher, risk is expressed as excess probability of contracting cancer over a lifetime $(70 \mathrm{yr})$ that gives potential concern for health risk. Our risk analyses also indicate that almost $70-90 \%$ of farmed milkfish is expected to well survive in milkfish farms in BFD-endemic area.

Our present toxicity bioassay data can be used extensively in the emerging field of ecological risk assessment. Nevertheless, 
probabilistic treatment of the model parameters, in conjunction with sensitivity analyses, should provide a rigorous basis for making sound environmental decisions. The concentrationresponse relationships can be viewed as integral in an overall scheme of ecological risk assessment involving bioaccumulation modeling. Concentration-response relationships will allow the substantial progress environmental toxicology of As to farmed milkfish to continue without losing touch with either the exposure-based information or the field-based observations of adverse responses and residue monitoring data.

It is our conclusion that the incorporation of probabilistic analysis into evaluation of exposure and concentration-response relationship greatly improves our ability to appraise the range of possible exposure scenarios and environmental risk to aquacultural species and human who consume contaminated fish. Probabilistic risk assessment will substantially reduce the compounded conservatism that is inherent in risk assessment that relies on conservative point value estimates for all bioaccumulation model, CBR toxicity model, TD-based Hill model, and human exposure parameters.

\section{References}

ATSDR. Toxicological profile for arsenic (update). Atlanta, GA: U.S. Public Health Service, Agency for Toxic Substances and Disease Registry; 2000.

Abernathy CO, Thomas DJ, Calderon RL. Health effects and risk assessment of arsenic. J Nutr 2003;133:1536-8.

Bourne DWA. Mathematical modeling of pharmacokinetic data. Lancaster (PA), USA: Technomic; 1995

Chen CM, Lee SZ, Wang JS. Metal contents of fish from culture ponds near scrap metal reclamation facilities. Chemosphere 2000;40:65-9.

Chen CJ, Hsueh YM, Tseng MP, Lin YC, Hsu LI, Chou HY, et al. In: Chappell WR, Abernathy CO, Calderon RL, editors. Arsenic exposure and health effects IV. Oxford, UK: Elsevier; 2001. p. 135-43.

Chou HN, Chung YC, Cho WC, Chen CY. Evidence of paralytic shellfish poisoning toxin in milkfish in south Taiwan. Food Addit Contam 2003;20:560-5.

Derendorf H, Hochhaas G. Handbook of pharmacokinetic pharmacodynamic correlation. Boca Raton, FL, USA: CRC Press; 1995.

Donohue JM, Abernathy CO. Exposure to inorganic arsenic from fish and shellfish. In: Chappell WR, Abernathy CO, Calderon RL, editors. Arsenic exposure and health effects. Oxford, UK: Elsevier; 1999. p. 89-98.

Finney DJ. Statistical method in biological assay. 3rd ed. London, England: Cambridge University Press; 1978. p. 508.

Fisheries Statistical Year Book. Fisheries administration, council of agriculture, executive Yuan: Taipei, Taiwan, R.O.C; 2003. p. 150-89.

Hermens JLM. Quantitative structure-activity relationships of environmental pollutants. In: Hutzinger O, editor. Handbook of environmental chemistry, vol. 2E. Berlin, Germany: Springer-Verlag; 1989. p. 111-62.
Han BC, Jeng WL, Chen RY, Fang GT, Hung TC, Tseng RJ. Estimation of target hazard quotients and potential health risks for metals by consumption of seafood in Taiwan. Arch Environ Contam Toxicol 1998;35:711-20.

Johnson W, Finley MT. Handbook of acute toxicity of chemicals to fish and aquatic invertebrates. United States Fish Wildlife Services Resource Publishing, vol. 137; 1980. p. 1-98.

Legierse KCHM, Verhaar HJM, de Bruijn JHM, Herman JLM. Analysis of the time-dependent acute aquatic toxicity of organo-phosphorus pesticides: the critical target occupation model. Environ Sci Technol 1999;33:917-25.

Lin MC, Liao CM, Liu CW, Singh S. Bioaccumulation of arsenic in aquacultural large-scale mullet Liza macrolepis from the blackfoot disease area in Taiwan. Bull Environ Contamin Toxicol 2001;67:91-7.

Lung SCC, Chen CF, Hu SC, Bau YP. Exposure of Taiwan residents to polychlorinated biphenyl congeners from farmed, ocean-caught, and imported fish. Environ Sci Technol 2003;37:4579-85.

Liao CM, Ling MP. Assessment of human health risks for arsenic bioaccumulation in tilapia (Oreochromis mossambicus) and large-scale mullet (Liza macrolepis) from blackfoot disease area in Taiwan. Arch Environ Contam Toxicol 2003;45:264-72.

Liao CM, Chen BC, Singh S, Lin MC, Liu CW, Han BC. Acute toxicity and bioaccumulation of arsenic in tilapia (Oreochromis mossambicus) from a blackfoot disease area in Taiwan. Environ Toxicol 2003;18:252-9.

McCarty LS, Mackay D. Enhancing ecotoxicological modeling and assessment. Environ Sci Technol 1993;27:1719-28.

Reinert RE, Knuth BA, Kamrin MA, Stober QJ. Risk assessment, risk management, and fish consumption advisories in the United States. Fisheries 1991;16:5-12.

Spehar RL, Fiandt JT, Anderson RL, Defore DL. Comparative toxicity of arsenic compounds and their accumulation in invertebrates and fish. Arch Environ Contam Toxicol 1980;9:53-63.

Sparks T, editor. Statistics in ecotoxicology. New York, NY: Wiley; 2000. p. 320.

Tsai JW, Liao CM. A dose-based modeling approach for accumulation and toxicity of arsenic in tilapia Oreschromis mossambicus. Environ Toxicol 2006;21:8-21.

USEPA. Risk assessment guidance for superfund: human health evaluation manual. USEPAWashington DC; 1989a. EPA-540/1-89-0002.

USEPA. Guidance manual for assessing human health risks from chemically contaminated fish and shellfish. Washington DC: USEPA; 1989b. EPA-503/ 8-89-002.

USEPA. Integrated risk information system on arsenic. Duluth, MN: USEPA; 1995.

USEPA. Exposure factors handbook. General factors. Washington DC: USEPA; 1997. EPA-600/P-95-002Fa.

USEPA. Technical progress report of the implementation plan for probabilistic ecological assessments: aquatic systems. Washington DC: USEPA; 2000.

Verhaar HJM, de Wolf W, Dyer S, Legierse KCHM, Seinen W, Hermens JLM. An LC50 vs time model for the aquatic toxicity of reactive and receptormediated compounds. Consequences for bioconcentration kinetics and risk assessment. Environ Sci Technol 1999;33:758-63.

Yu WH, Harvey CM, Harvey CF. Arsenic in groundwater in Bangladesh: a geostatistical and epidemiological framework for evaluating health effects and potential remedies. Water Resour Res 2003;39:1146-63. 